\title{
Produção de mudas de Zinia elegans em substratos à base de resíduos agroindustriais e agropecuários em diferentes tamanhos de recipientes ${ }^{(1,2)}$
}

\author{
HELON HÉBANO DE FREITAS SOUSA (3), FRED CARVALHO BEZERRA (4), RAIMUNDO NONATO DE ASSIS JÚNIOR ${ }^{(5)}$, \\ FERNANDO VASCONCELLOS MEYER FERREIRA(6), TIAGO DA COSTA SILVA ${ }^{(6)}$, LINDBERG ARAÚJO CRISÓSTOMO ${ }^{(4)}$
}

\section{RESUMO}

\begin{abstract}
O substrato e o tamanho do recipiente são fatores importantes para a obtenção de mudas de qualidade. Os objetivos desse trabalho foram testar oito substratos e três tipos de recipientes na produção de mudas de zínia. Os substratos foram formulados com os seguintes compostos: bagaço de cana e esterco bovino (composto 1); lixo de frutas e de verduras mais esterco bovino (composto 2); e pó da casca de coco verde, bagana de carnaúba e solo. O experimento foi conduzido em condições de casa de vegetação, e os substratos testados foram: $\mathrm{S} 1=$ composto $1+$ bagana + solo (1:2:1); $\mathrm{S} 2=$ composto $1+$ pó de coco verde + solo $(1: 2: 1) ; \mathrm{S} 3=$ composto $1+$ bagana $(1: 1) ; \mathrm{S} 4=$ composto $1+$ pó de coco verde $(1: 1) ; \mathrm{S} 5=$ composto 2 puro; $\mathrm{S} 6=$ composto 2 + bagana (1:1); $\mathrm{S} 7=$ composto 2 + pó de coco verde (1:1); e $\mathrm{S} 8=$ substrato comercial. Os recipientes testados foram bandejas plásticas com 228 (14 ml/célula), 150 (19 ml/célula) e 126 células (30 ml/célula), respectivamente. A percentagem de germinação foi semelhante para todos os substratos e bandejas testados. Os substratos S1 e S8 e a bandeja com 126 células mostraram os melhores resultados para as variáveis altura, massa seca da parte aérea e percentagem de sobrevivência da mudas.
\end{abstract}

Palavras-chave: floricultura, compostagem, reciclagem.

ABSTRACT

Production of Zínia elegans seedlings using organic by-products as substrate in different container size

The substrate and container size are very important factors to obtain seedlings of good quality. The objectives of this study were to test eight substrates and three container sizes on the production of Zinia seedlings. The substrates were formulated by composing sugar cane bagace + bovine manure (compost 1 ), compost from fruits and vegetables waste + bovine manure (compost 2), green coir dust, wax palm straw and soil. The experiment was carried out under greenhouse conditions and the substrates tested were: $\mathrm{S} 1=$ compost $1+$ wax palm straw + soil $(1: 2: 1), \mathrm{S} 2=$ compost $1+$ green coir dust + soil $(1: 2: 1), \mathrm{S} 3=$ compost $1+$ wax palm straw (1:1), S4= compost $1+$ green coir dust (1:1), $\mathrm{S} 5=$ only compost $2, \mathrm{~S} 6=$ compost $2+$ wax palm straw (1:1), $\mathrm{S} 7=$ compost $2+$ green coir dust and $\mathrm{S} 8=$ commercial substrate. The container tested were plastic trays with 228 cells $(14 \mathrm{ml} /$ cell $), 150$ cells $(19 \mathrm{ml} /$ cell $)$ and 126 cells $(30 \mathrm{ml} /$ cell) respectively. The percentage of seed germination was similar for all substrates and trays. The substrates S1 and S8 and tray with 126 cells $(30 \mathrm{ml} /$ cell) showed the best results for height, shoot dry matter and survival percentage of the seedlings.

Keywords: floriculture, composting, recycling.

\section{INTRODUÇÃO}

A floricultura ganhou um impulso significativo nos últimos anos, principalmente na região Nordeste, onde a produção e a comercialização vêm apresentando um incremento significativo na economia regional. Junto com esse aumento, surgiu a necessidade de estudos que viabilizassem essa atividade, tornando-a rentável e atrativa aos produtores. Por ser uma atividade intensiva com custos relativamente elevados, a utilização de mudas de qualidade é essencial para o sucesso na exploração de qualquer espécie ornamental. Nesse contexto, o substrato e o tamanho do recipiente onde são produzidas as mudas são muito importantes.

Os produtores e viveiristas do Nordeste enfrentam problemas com o alto custo de insumos, incluindose os substratos, cuja produção está concentrada nas regiões Sul e Sudeste do Brasil, chegando seu preço no nordeste a triplicar em relação às aludidas regiões. No Nordeste brasileiro, vários resíduos rurais e urbanos com potencial para serem utilizados na agricultura já são usados por produtores agrícolas dessa região, porém a utilização desses materiais nem sempre apresenta bons resultados, pois suas características são desconhecidas e faltam estudos que possibilitem utilizá-los de forma racional para garantir a sustentabilidade econômica dos produtores em consonância com os princípios e objetivos do desenvolvimento sustentável.

A geração de resíduos, que é inerente à atividade do ser humano, constitui atualmente um dos grandes problemas enfrentados pelo homem, representando riscos para o ambiente e para a população, devido, principalmente, à contaminação das reservas hídricas e do solo, como também proporcionando um ambiente favorável para proliferação de organismos nocivos ao homem. Sua destinação é motivo de preocupação há algum tempo, porém, ela se agravou

\footnotetext{
(1) Recebido em 24/07/2010 e aceito para publicação em 21/10/2010;

(2) Parte da dissertação de mestrado do primeiro autor;

(3) Aluno de Pós-Graduação em Solos e Nutrição de Plantas ESALQ/USP, Av. Pádua Dias 11, CEP 13418-900, Piracicaba (SP), hhfsousa@gmail.com; (4) Eng ${ }^{\circ}$ Agrônomo Dr.Sc Pesquisador da Embrapa Agroindústria Tropical, Rua Dra. Sara Mesquita, 2270, CEP 60.511-110, Fortaleza/CE, fred@cnpat. embrapa.br; Eng ${ }^{\circ}$ Agrônomo Dr. Sc Pesquisador da Embrapa Agroindústria Tropical, lindberg@cnpat.embrapa.br;

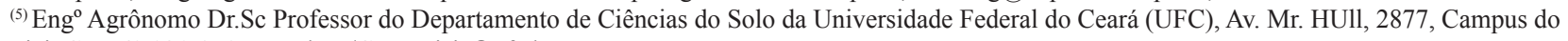
Pici, CEP 60.021-970, Fortaleza/CE, assisjr@ufc.br;

${ }^{(6)}$ Aluno de Graduação em Agronomia da UFC.
} 
com o surgimento dos grandes centros urbanos nas últimas décadas. Segundo MELO et al. (2000), a geração de lixo é um dos fatores que mais contribuem para a degradação do ambiente.

A reciclagem de materiais descartados é uma maneira de se evitar e/ou reduzir o efeito negativo destes resíduos, contribuindo com o desenvolvimento sustentável, agregando valores e diminuindo a utilização dos recursos naturais. São resíduos que podem servir de adubo e/ou substrato através do processo de compostagem.

Muitos materiais podem ser usados como substrato agrícola. Nesse sentido, estudos de ABAD et al. (2001) mostraram que de 105 materiais (resíduos) por eles avaliados, 63 apresentaram potencial para uso como substrato para espécies ornamentais. Substrato pode ser definido como o meio de cultivo de plantas em recipientes que podem ser constituídos por um ou vários materiais em misturas, inclusive resíduos diversos, devendo oferecer condições favoráveis para o bom crescimento das plantas.

No caso de produção de mudas, o volume dos recipientes exerce grande influência sobre o seu desenvolvimento, principalmente no que se refere à área de exploração pelas raízes, disponibilizando mais ou menos água e nutrientes para elas. A determinação do volume ideal dos recipientes para produção de mudas pode ser um grande diferencial no custo de produção, pois isso implica diretamente a quantidade de substrato que será utilizado.

Segundo CUNHA et al. (2005), recipientes de maiores volumes oferecem melhores condições para o desenvolvimento das mudas, contudo, eles somente devem ser utilizados para espécies que apresentem desenvolvimento lento, necessitando permanecer no viveiro por um longo tempo, ou quando se desejam mudas bem desenvolvidas. Segundo BEZERRA (2003), recipientes de menor volume reduzem o crescimento e o vigor das mudas e ainda restringem o desenvolvimento de sistema radicular, e mudas produzidas em recipientes pequenos, normalmente, são menores e menos vigorosas do que aquelas produzidas em recipientes maiores.

A espécie Zinnia elegans Jacq. é uma planta herbácea, anual, de pleno sol, pertencente à família Asteraceae, popularmente conhecida como capitão, moça e velha ou canela-de-velho, apresenta flores do tipo margarida simples, dobrado ou crespo, sendo utilizada em parques e jardins de regiões tropicais e subtropicais. É uma ornamental cultivada também para a produção de flor de corte devido à sua longa durabilidade, sendo adequada também para a utilização em bordaduras e maciços a pleno sol em regiões de temperatura amena e áreas tropicais.

Os objetivos deste trabalho foram avaliar substratos formulados a partir de resíduos orgânicos de atividades agropecuárias e agroindustriais, compostados ou não, na produção de mudas de Zinia elegans, em diferentes tamanhos de recipientes.

\section{MATERIAL E MÉTODOS}

O experimento foi conduzido em casa de vegetação situada nas dependências da Embrapa-CNPAT, sediada na cidade de Fortaleza, CE, Brasil.

O processo de compostagem dos resíduos orgânicos foi conduzido de acordo com Kiehl (2002) em anéis de concreto, acomodados em ambiente coberto e pavimentado com cimento. Foram formulados dois compostos: Composto 01: Resíduos da Ceasa + esterco de gado (3:1) e Composto 02: Bagaço de cana + esterco de gado (3:1).

Os resíduos provenientes da Ceasa eram constituídos por materiais impróprios para consumo humano, como restos de verduras, frutas e legumes. $\mathrm{O}$ bagaço de cana foi proveniente da indústria de açúcar e álcool da região.

No processo de compostagem, esses materiais foram triturados (entre 5 e $10 \mathrm{~cm}$ ) e homogeneizados, em seguida, misturados com o esterco e colocado, em anéis de concreto protegido com telas para evitar a entrada de pequenos animais e insetos. Foi feito o monitoramento da temperatura e da umidade, sendo controladas com revolvimentos e irrigações sempre que necessário. $\mathrm{O}$ processo de compostagem teve duração de 60 dias, quando não mais foi observada variação na temperatura.

Após a compostagem, foram determinadas as condutividades elétricas $\left(\mathrm{CE}_{\mathrm{es}}\right)$ dos compostos 01 e 02 , que apresentaram, respectivamente, 3,0 e $0,91 \mathrm{dS} \cdot \mathrm{m}^{-1}$, e com base nesses valores foram determinadas as proporções na composição dos substratos testados. Para determinação da $\mathrm{CE}_{\mathrm{es}}$, foi utilizada a solução extraída, após agitação, de uma mistura de substrato e água na relação de 1:5 (volume/ volume).

Os substratos avaliados no trabalho foram formulados a partir dos produtos obtidos ao término do processo de compostagem, puros ou em misturas com outros materiais orgânicos ou solo: Substrato 01: Composto 01 + bagana de carnaúba + solo (1:2:1); Substrato 02: Composto $01+$ pó de coco verde + solo (1:2:1); Substrato 03: Composto 01 + bagana de carnaúba (1:1); Substrato 04: Composto $01+$ pó de coco verde (1:1); Substrato 05: Composto 02 puro; Substrato 06: Composto 02 + Bagana de carnaúba (1:1); Substrato 07: Composto $02+$ pó de coco verde (1:1); e Substrato 08: Comercial (Hortimix).

Após a formulação dos substratos, foram coletadas amostras para determinação dos atributos químicos, seguindo a metodologia usada pelo Laboratório de Solos e Água da Embrapa-CNPAT, que é baseada na Instrução Normativa $\mathrm{N}^{\circ} 46$ do Ministério da Agricultura, Pecuária e Abastecimento. Todas as análises foram feitas em três repetições.

Os recipientes testados foram bandejas de poliestireno laminado com 126 células (volume $30 \mathrm{ml} /$ célula), R1; com 150 células (volume $19 \mathrm{ml} /$ célula), R2; e com 228 células (volume $14 \mathrm{ml} /$ célula), R3.

A semeadura foi feita colocando-se três sementes de zínia por célula, deixando-se apenas uma planta após o raleio. Após a germinação, as plantas foram levadas para uma casa de vegetação sombreada a 50 \% e mantidas neste ambiente durante toda a duração do experimento.

A irrigação foi realizada com um pulverizador manual, objetivando maior uniformidade na distribuição da água de acordo com a necessidade, até que a água começasse a escorrer pelo orifício da célula, sem, no entanto, ocorrer lixiviação (lavagem do substrato).

O experimento teve duração de 21 dias, tempo necessário para que as plântulas atingissem o tamanho para transplantio $(5 \mathrm{~cm})$. 
Foi avaliada a percentagem de germinação no $7^{\circ}$ dia após o semeio, e de acordo com informações na embalagem das sementes a germinação da espécie ocorria entre 5-10 dias após o semeio. E ao final do experimento (21 dias), foram avaliados a percentagem de sobrevivência, altura, número de folhas e produção de massa seca das mudas. A massa seca foi determinada após ter sido retirado o substrato aderido às raízes e em seguida seca em estufa a $65^{\circ} \mathrm{C}$ até massa constante.

O delineamento experimental utilizado no trabalho foi o inteiramente casualizado com três tratamentos nas parcelas principais (tamanho de recipiente) e oito tratamentos nas subparcelas (substratos), em quatro repetições. Foram consideradas dez plantas como uma unidade experimental em esquema de parcelas subdivididas. Cada bandeja contou com uma bordadura. Os resultados obtidos de todas as variáveis estudadas foram submetidos à análise de variância pelo teste $\mathrm{F}$, sendo as médias comparadas pelo teste de Tukey a $5 \%$ de probabilidade.

\section{RESULTADOS E DISCUSSÃO}

A percentagem de germinação das sementes (Tabela 3) foi semelhante para todos os substratos e recipientes testados, com exceção do substrato S2, mostrando que os substratos apresentaram condições favoráveis ao processo germinativo, como disponibilidade adequada de água e ar. A germinação é influenciada, além dos fatores inerentes à semente (dormência), por condições ambientais como luz, temperatura, disponibilidade de água e oxigênio. A disponibilidade de água e oxigênio no substrato está relacionada com a textura, substratos com textura grosseira retêm menos água do que aqueles que apresentam granulometria mais fina; por outro lado, substratos que têm em sua composição partículas pequenas, implicando uma predominância de microporosidade, podem comprometer a disponibilidade de oxigênio necessário à germinação. O substrato adequado para germinação deve apresentar um equilíbrio entre a macro e a microporosidade, o que promove uma boa disponibilidade de água e oxigênio. De acordo com FERREIRA et al. (2008), um bom substrato deve proporcionar condições ideais para uma maior taxa de germinação e favorecer o crescimento das raízes.

Com relação à sobrevivência das mudas, observou-se, com exceção do S3, que os demais substratos se igualaram estatisticamente ao substrato comercial. Os resultados mostram que os maiores valores para as variáveis altura e produção de massa seca da parte aérea foram observados em mudas produzidas no substrato 01 (composto $01+$ bagana + solo) e no substrato 08 (comercial), respectivamente, não havendo diferença estatística entre eles, seguido daqueles produzidos nos substratos 03 (composto 01 + bagana) e 06 (composto $02+$ bagana).

Os resultados da germinação, sobrevivência, altura e massa seca foram iguais estatisticamente àqueles encontrados para as mudas produzidas no substrato comercial. O substrato S1 foi formulado com composto orgânico de resíduos da Ceasa, constituído por uma grande variedade de frutas e verduras frescas, o que pode ter conferido a esse composto uma melhor qualidade nutricional quando comparado ao composto 02 , formado por um material mais fibroso e de difícil compostagem, o bagaço de cana-de-açúcar. Os substratos S1 e S8 apresentaram teores de nitrogênio, cálcio e magnésio maiores do que os demais substratos (Tabela 2).

$\mathrm{O}$ substrato que apresentou o segundo melhor resultado para as variáveis altura e produção de massa seca foi o S3, e para variável altura, ele foi igual ao S6; para a variável massa seca, o substrato S6 apresentou resultados inferiores ao substrato $\mathrm{S} 3$. O resíduo comum na composição dos substratos S1, S2, S3 e S6 é a bagana de carnaúba, subproduto da extração do pó da palha de carnaúba para produção de cera, utilizado, empiricamente, como cobertura morta na produção de hortaliças e recentemente na produção de plantas ornamentais, tendo esse resíduo favorecido o crescimento das mudas nos substratos que o continham. Esse efeito pode estar relacionado com a melhoria das propriedades físicas dos substratos, principalmente na macro e microporosidade, devido ao tamanho de suas partículas, ou ainda, ao aporte de nutrientes pela bagana. Pode-se observar relação entre a presença desse componente, independentemente dos compostos $01 \mathrm{e}$ 02, e uma maior disponibilidade de alguns minerais como o nitrogênio, o fósforo e o potássio em relação àqueles formulados com os compostos 01 e 02 misturados ao pó de coco verde. TERCEIRO NETO (2004), estudando os teores de nutrientes totais, nutrientes solúveis em água e em Mehlich 1 em diferentes substratos na produção de mudas de violeta africana (Saintpaulia ionantha Wendl), observou que a bagana de carnaúba apresentou teores de nutrientes próximos àqueles observados nos substratos comerciais testados no mesmo trabalho, principalmente N, P e K.

Para os demais substratos, os valores para essas variáveis foram estatisticamente inferiores aos substratos S1, S8, S3 e S6 e semelhantes entre si. Isso pode estar relacionado à baixa disponibilidade de nutrientes nos substratos S2 (composto $01+$ pó de coco verde + solo), S4 (composto 01 + pó de coco verde), S5 (composto 02 puro) e S7 (composto 02 + pó de coco verde).

De uma maneira geral, os substratos formulados com o composto 01 e bagana de carnaúba apresentaram os valores mais promissores, próximos ou iguais aos resultados obtidos com o substrato comercial para as variáveis testadas. LEAL et al. (2007) observaram melhores resultados na produção de mudas de alface, beterraba e tomate utilizando compostos orgânicos em comparação com um substrato comercial.

O número de folhas das mudas segue a mesma tendência do que foi observado nas variáveis altura e massa seca. Observa-se que apenas as plantas produzidas nos substratos 01 e 08 apresentaram o segundo par de folhas definitivas, seguidas pelas plantas do substrato 03, diferentemente dos demais substratos que, em sua maioria, apresentaram apenas o primeiro par de folhas definitivas.

Com relação à caracterização dos substratos, os valores de $\mathrm{pH}$ (Tabela 1), em sua maioria, encontram-se fora das faixas consideradas ideais para meios de crescimento de acordo com VERDONCK et al. (1981), que sugerem uma faixa de 5,0 a 5,8; PENNINGSFELD (1978), de 5,5 a 6,5; VERDONCK (1983), de 4,0 a 6,5; e VERDONCK e GRABRIELS (1988), de 4,5 a 6,0. BENITO et al. (2006), trabalhando com substratos à base de compostados, 
encontraram valores superiores às faixas ótimas para meios de crescimento de plantas e sugeriram a mistura desses produtos a outros materiais que favoreçam a diminuição do pH desses substratos.

O substrato 03 apresentou a maior condutividade elétrica, 1,88 dS m $\mathrm{m}^{-1}$ (Tabela 1), observando-se influência da bagana no aumento desta variável. Comparando-se os valores das Ce do S1 e S2, nota-se que a presença da bagana foi responsável pelo ligeiro aumento da condutividade no substrato 01 . Isso pode ser observado também quando comparados entre si os substratos 03 e 04, 06 e 07.

Os menores valores da CTC (Tabela 1) foram observados nos substratos 01 e 02 , indicando que a presença de material mineral no substrato foi responsável por esses baixos valores.

Diferentemente, os substratos formulados exclusivamente por material orgânico apresentaram valores de CTC elevados em virtude da grande superfície específica dos coloides orgânicos. O maior valor da CTC foi observado no composto comercial.

Segundo os dados de sobrevivência, altura e produção de massa seca, observa-se que os diferentes tipos de recipiente influenciaram no desenvolvimento das mudas para essas variáveis, pois apresentam diferença significativa entre os tratamentos. Os resultados mais promissores foram aqueles observados nas mudas produzidas nas bandejas que continham células de $30 \mathrm{ml}$, seguidas daquelas produzidas em células de 19 e $14 \mathrm{ml}$ para todos os substratos.

Resultados semelhantes aos encontrados nesse trabalho foram observados na aclimatização de mudas micropropagadas de abacaxi ornamental, em que foram usados diversos tamanhos de recipientes (BOMFIM, 2006). Segundo o autor, a superioridade dos recipientes de maior volume no desenvolvimento das plantas está diretamente relacionada às características intrínsecas dos recipientes como altura e capacidade volumétrica, traduzidas numa maior área para exploração pelas raízes, consequentemente, mais nutrientes, além da melhoria nas qualidades físicas como o espaço de aeração.

TELLES et al. (2005), estudando diferentes volumes de substrato no desenvolvimento de Targetes patula, observaram que as plantas no maior volume de substrato apresentaram maior massa fresca e seca da parte aérea, sugerindo que o tamanho do recipiente influencia na disponibilidade de água e nutrientes e, consequentemente, no desenvolvimento da planta.

Esses dados demonstram a importância da quantidade de substrato a ser explorado pelas raízes para produção de mudas de qualidade, pois recipientes maiores permitem um maior volume de raízes, aumentando a área de absorção de nutrientes. A utilização de uma adubação suplementar pode contornar esse problema de diminuição dos nutrientes devido à menor quantidade de substrato disponível, outros trabalhos mais específicos poderiam obter uma confirmação desse aspecto.

Atualmente existem diversas empresas especializadas na produção de mudas de hortaliças e plantas ornamentais. Essas empresas fornecem seus produtos para consumidores de diversas regiões do país, incluindo no preço final do produto o valor do transporte, que geralmente é calculado com base no peso ou volume da mercadoria. O uso de recipientes menores funciona como uma alternativa a esse problema, diminuindo o peso e volume por muda, porém, segundo BEZERRA (2003), recipientes de menor volume reduzem o crescimento e o vigor das mudas e ainda restringem o desenvolvimento de sistema radicular. Mudas produzidas em recipientes pequenos, normalmente, são menores e menos vigorosas do que aquelas produzidas em recipientes grandes.

Portanto, a escolha do tipo de recipiente a ser utilizado na formação de mudas deve ser baseada no custo de aquisição, na durabilidade do material, no tamanho e na forma, na facilidade de operação, na área ocupada dentro da área de cultivo e nas características para formação de mudas de boa qualidade (GONÇALVES, 1995; MACEDO, 1993).

Os resultados observados no trabalho sugerem que o recipiente R3 (126 células) e os substratos S1 (composto $1+$ bagana + solo) e S8 (Hortimix) testados podem ser usados na produção de mudas de Zinnia elegans. O uso de resíduos na formulação de substratos implica diminuição dos custos de produção, reduzindo o impacto ambiental produzido pelo descarte desses materiais em lixões.

\section{REFERÊNCIAS}

ABAD, M; NOGUERA, P.; BURÉS, S. National inventory of organic waste for use as growing media for ornamental potted plant production: case study in Spain. Bioresource Technology, n. 77, p. $197-200,2001$.

BENITO, M.; MASAGUER, A.; MOLINER, A.; ANTONIO, R. de. Chemical and physical properties of pruning waste compost and their seazonal variability. Bioresource technology, n.97, p.2071-2076, 2006.

BEZERRA, F.C. Produção de mudas de hortaliças em ambiente protegido. Fortaleza: Embrapa Agroindústria Tropical, 2003. 22p. (Documentos, 72).

BOMFIM, G.V. do. Efeito de lâminas e frequências de irrigação e tipos e volumes de substrato na aclimatação de mudas micropropagadas de abacaxizeiro ornamental. 167 f. il. color. enc. Dissertação (Mestrado em irrigação e drenagem) - Universidade Federal do Ceará, Fortaleza. 2006.

CUNHA, A.O.; ANDRADE, L.A. de; BRUNO R. L. A.; SILVA, J. A. L. da; SOUZA, V.C. de; Efeitos de substratos e das dimensões dos recipientes na qualidade das mudas de Tabebuia impetiginosa (Mart. Ex D.C.) Standl. Revista Árvore, Viçosa, v.29, n.4, p.507-516, 2005.

FERREIRA, E.G.B. de S.; MATOS, V.P.; SENA, L.H.de M.; SALES, A.G.F.A. Germinação de sementes e desenvolvimento de plântulas de crista de galo em diferentes substratos. Scientia Agraria, Curitiba, v.9, n.2, p.241-244, 2008.

GONÇALVES, A.L. Substratos para produção de mudas de plantas ornamentais. In: MINAMI, K. (Ed). Produção 
de mudas de qualidade em horticultura. São Paulo: T.A. Queiroz, 1995. 135p.

KIEHL, E. J. Conceitos sobre compostagem. In: Manual de Compostagem. Piracicaba: E.J. Kiehl, 3a edição do autor, 2002, p. $01-03.171$ p.

LEAL, M.A de A.; GUERRA, J.G.M.; PEIXOTO, R.T.G.; ALMEIDA, D.L. Utilização de compostos orgânicos como substrato na produção de mudas de hortaliças. Revista Horticultura Brasileira, v.25, n.3, p.392-395, 2007.

MACEDO, A.L. Produção de mudas em viveiros florestais: espécies nativas. São Paulo: Fundação Florestal, 1993. 18 p.

MELO, W.J. de, MARQUES, O.M.O.; MELO, V.P. de; CINTRA, A. A.D. Uso de resíduos em hortaliças e impacto ambiental. Revista Horticultura Brasileira, Brasília, v. 18, suplemento julho, p. $67-82,2000$.

PENNINGSFELD, F. Substrates for protected cropping. Acta Horticulturae, v.82, p.13-22, 1978.
TELLES, C.A.; MIELK, É. C.; MACHADO, M.P.; BIASE, L.A. Diferentes volumes de substrato no desenvolvimento de plantas de cravo de defunto (Targetes patula L). Revista Brasileira de Horticultura Ornamental, Campinas, v.11,n.1, p. 67-71, 2005.

TERCEIRO NETO, C.P.C. Efeito da concentração da solução nutritiva e do substrato na aclimatação de plantas micropropagadas de violeta, 2004. 51 f. il. Dissertação (Mestrado em Solos e Nutrição de Plantas) - Universidade Federal do Ceará, Fortaleza. 2004.

VERDONCK, O; De VLEESCHAUWER, D; De BOODT, M. The influence of the substrate to plant growth. Acta Horticulturae, Wageningen, n. 126, p.251-258, 1981.

VERDONCK, O.; Reviewing and evaluation of new material used as substrates. Acta Horticulturae, Wageningen, n.150, p.467-473, 1983.

VERDONCK, O.; GABRIELS, R. Substrate requiriments for plants. Acta Horticulturae, Wageningen, n.221 , p.1923, 1988 .

Tabela 1. pH, CE e CTC dos substratos testados

Table 1. pH, EC and CEC of tested substrates

\begin{tabular}{cccc}
\hline Substrato & $\mathrm{pH}$ & $\begin{array}{c}\mathrm{Ce} \\
\mathrm{dS} . \mathrm{m}-1\end{array}$ & $\begin{array}{c}\text { CTC } \\
\text { mmolc.L-1 }\end{array}$ \\
\hline SI & $6,4 \mathrm{bc}$ & $1,27 \mathrm{c}$ & $85,71 \mathrm{~g}$ \\
S2 & $7,3 \mathrm{abc}$ & $0,88 \mathrm{~d}$ & $109,75 \mathrm{f}$ \\
S3 & $7,5 \mathrm{ab}$ & $1,88 \mathrm{a}$ & $165,22 \mathrm{~d}$ \\
S4 & $7,2 \mathrm{abc}$ & $1,58 \mathrm{~b}$ & $242,22 \mathrm{~b}$ \\
S5 & $7,7 \mathrm{a}$ & $0,91 \mathrm{~d}$ & $176,26 \mathrm{~cd}$ \\
S6 & $6,5 \mathrm{bc}$ & $0,71 \mathrm{e}$ & $143,80 \mathrm{e}$ \\
S7 & $7,3 \mathrm{abc}$ & $0,60 \mathrm{e}$ & $191,29 \mathrm{c}$ \\
S8 & $6,2 \mathrm{c}$ & $0,98 \mathrm{~d}$ & $341,88 \mathrm{a}$ \\
\hline C.V. $(\%)$ & 5,595 & 3,627 & 3,397 \\
\hline
\end{tabular}

Valores seguidos de uma mesma letra nas colunas não diferem entre si pelo teste de Tuckey $(\mathrm{p}<0,05)$

S1: composto $01+$ bagana + solo (1:2:1); S2: composto $01+$ pó de coco verde + solo (1:2:1); S3: composto 01 + bagana (1:1); S4: composto 01 + pó de coco verde; S5: composto 02 puro; S6: composto 02 + bagana (1:1); S7: composto 02 + pó de coco verde; S8: comercial. 
Tabela 2. Teores de nutrientes solúveis em água presentes nos substratos testados

Table 2. Water soluble nutrients content on tested substrates

\begin{tabular}{|c|c|c|c|c|c|c|c|c|c|}
\hline \multirow{2}{*}{ Substrato } & $\mathrm{N}-\mathrm{NH}^{4+}$ & $\mathrm{N}^{-\mathrm{NO}^{3-}}$ & $\mathrm{P}$ & K & $\mathrm{Ca}$ & $\mathrm{Mg}$ & $\mathrm{Na}$ & $\mathrm{S}$ & $\mathrm{Cl}$ \\
\hline & \multicolumn{9}{|c|}{ g. $\mathrm{L}^{-1}$} \\
\hline SI & $0,026 \mathrm{a}$ & $0,179 \mathrm{~b}$ & $0,307 \mathrm{~b}$ & $1,245 \mathrm{~b}$ & $0,043 \mathrm{~b}$ & $0,058 \mathrm{~b}$ & $0,149 \mathrm{c}$ & $0,118 \mathrm{c}$ & $1,388 \mathrm{a}$ \\
\hline S2 & $0,010 \mathrm{bc}$ & $0,003 \mathrm{e}$ & $0,340 \mathrm{a}$ & $0,854 \mathrm{c}$ & $0,018 \mathrm{~d}$ & $0,031 \mathrm{e}$ & $0,149 \mathrm{c}$ & $0,103 \mathrm{~cd}$ & $0,679 \mathrm{bc}$ \\
\hline $\mathrm{S} 3$ & $0,011 \mathrm{~b}$ & $0,136 \mathrm{c}$ & $0,267 \mathrm{~cd}$ & $2,583 \mathrm{a}$ & $0,034 \mathrm{c}$ & $0,056 \mathrm{~b}$ & $0,224 \mathrm{~b}$ & $0,231 \mathrm{~b}$ & $1,477 \mathrm{a}$ \\
\hline S4 & $0,003 \mathrm{~d}$ & $0,119 \mathrm{~d}$ & $0,205 \mathrm{e}$ & $1,120 \mathrm{~b}$ & $0,025 \mathrm{~d}$ & $0,024 \mathrm{f}$ & $0,268 \mathrm{a}$ & $0,221 \mathrm{~b}$ & $1,388 \mathrm{a}$ \\
\hline S5 & $0,006 \mathrm{~cd}$ & $0,002 \mathrm{e}$ & $0,274 \mathrm{c}$ & $0,847 \mathrm{c}$ & $0,051 \mathrm{~b}$ & $0,040 \mathrm{~d}$ & $0,168 \mathrm{c}$ & $0,097 \mathrm{~d}$ & $1,270 \mathrm{a}$ \\
\hline S6 & $0,014 \mathrm{~b}$ & $0,005 \mathrm{e}$ & $0,258 \mathrm{~cd}$ & $1,185 \mathrm{~b}$ & $0,026 \mathrm{~cd}$ & $0,051 \mathrm{c}$ & $0,108 \mathrm{~d}$ & $0,116 \mathrm{~cd}$ & $0,679 \mathrm{bc}$ \\
\hline S7 & $0,002 \mathrm{~d}$ & $0,005 \mathrm{e}$ & $0,243 \mathrm{~d}$ & $0,656 \mathrm{~d}$ & $0,019 \mathrm{~d}$ & $0,017 \mathrm{~g}$ & $0,153 \mathrm{c}$ & $0,057 \mathrm{e}$ & $0,590 \mathrm{c}$ \\
\hline S8 & $0,028 \mathrm{a}$ & 0,229 a & $0,119 \mathrm{f}$ & $0,585 \mathrm{~d}$ & $0,078 \mathrm{a}$ & $0,075 \mathrm{a}$ & $0,034 \mathrm{e}$ & $0,307 \mathrm{a}$ & $0,856 \mathrm{~b}$ \\
\hline C.V. (\%) & 13,58 & 6,32 & 3,337 & 4,378 & 7,945 & 4,294 & 6,819 & 4,808 & 8,862 \\
\hline
\end{tabular}

Valores seguidos de uma mesma letra nas colunas não diferem entre si pelo teste de Tuckey $(\mathrm{p}<0,05)$

S1: composto $01+$ bagana + solo $(1: 2: 1) ;$ S2: composto $01+$ pó de coco verde + solo $(1: 2: 1) ;$ S3: composto $01+$ bagana (1:1); S4: composto 01 + pó de coco verde; S5: composto 02 puro; S6: composto 02 + bagana (1:1); S7: composto 02 + pó de coco verde; S8: comercial.

Tabela 3. Percentagem de germinação de sementes, percentagem de sobrevivência, altura e massa seca de mudas de Zinia elegans em diferentes substratos e tamanhos de recipientes

Table 3. Seed germination percentage, survival percentage, height and dry matter of Zinia elegans seedlings in different substrates and container size

\begin{tabular}{|c|c|c|c|c|c|c|c|c|c|}
\hline \multicolumn{10}{|c|}{ Substrato } \\
\hline & $\mathrm{S} 1$ & $\mathrm{~S} 2$ & $\mathrm{~S} 3$ & S4 & S5 & S6 & S7 & S8 & Média \\
\hline \multicolumn{10}{|c|}{ Germinação (\%) } \\
\hline $\mathrm{R} 1$ & 100 & 95 & 100 & 100 & 100 & 100 & 100 & 100 & $99,37 \mathrm{a}$ \\
\hline $\mathrm{R} 2$ & 100 & 100 & 100 & 100 & 100 & 100 & 100 & 100 & $100,00 \mathrm{a}$ \\
\hline R3 & 100 & 100 & 100 & 100 & 100 & 100 & 100 & 100 & $100,00 \mathrm{a}$ \\
\hline Média & $100,00 \mathrm{~A}$ & $98,33 \mathrm{~B}$ & $100,00 \mathrm{~A}$ & $100,00 \mathrm{~A}$ & $100,00 \mathrm{~A}$ & $100,00 \mathrm{~A}$ & $100,00 \mathrm{~A}$ & $100,00 \mathrm{~A}$ & \\
\hline \multicolumn{10}{|c|}{ Sobrevivência (\%) } \\
\hline $\mathrm{R} 1$ & 97,5 & 80 & 75 & 95 & 95 & 87,5 & 97,5 & 90 & $89,69 \mathrm{~b}$ \\
\hline $\mathrm{R} 2$ & 100 & 100 & 67,5 & 97,5 & 97,5 & 90 & 95 & 95 & $92,81 \mathrm{ab}$ \\
\hline R3 & 95 & 92,5 & 90 & 100 & 100 & 97,5 & 100 & 100 & $96,87 \mathrm{a}$ \\
\hline Média & $97,50 \mathrm{~A}$ & $90,83 \mathrm{AB}$ & $77,50 \mathrm{~B}$ & $97,50 \mathrm{~A}$ & $97,50 \mathrm{~A}$ & $91,67 \mathrm{~A}$ & $97,50 \mathrm{~A}$ & $95,00 \mathrm{~A}$ & \\
\hline \multicolumn{10}{|c|}{ Altura $(\mathrm{mm})$} \\
\hline $\mathrm{R} 1$ & 61,35 & 36,72 & 47,55 & 38,84 & 43,28 & 44,12 & 40,86 & 55.40 & $46,02 \mathrm{~b}$ \\
\hline $\mathrm{R} 2$ & 53,17 & 41,71 & 44,41 & 37,39 & 44,26 & 49,61 & 44,85 & 50,66 & $45,71 \mathrm{~b}$ \\
\hline R3 & 61,87 & 37,91 & 42,47 & 41,48 & 44,75 & 47,6 & 42,73 & 60,03 & $48,61 \mathrm{a}$ \\
\hline Média & $58,80 \mathrm{~A}$ & $38,78 \mathrm{C}$ & $48,15 \mathrm{~B}$ & $39,23 \mathrm{C}$ & $44,10 \mathrm{BC}$ & $47,11 \mathrm{~B}$ & $42,69 \mathrm{BC}$ & $55,36 \mathrm{~A}$ & \\
\hline \multicolumn{10}{|c|}{ Massa seca (g) } \\
\hline $\mathrm{R} 1$ & 0,347 & 0,122 & 0,248 & 0,125 & 0,144 & 0,149 & 0,122 & 0,330 & $0,198 \mathrm{c}$ \\
\hline $\mathrm{R} 2$ & 0,428 & 0,149 & 0,325 & 0,130 & 0,143 & 0,191 & 0,153 & 0,395 & $0,239 b$ \\
\hline R3 & 0,520 & 0,141 & 0,381 & 0,150 & 0,166 & 0,197 & 0,153 & 0,629 & $0,292 \mathrm{a}$ \\
\hline Média & $0,431 \mathrm{~A}$ & $0,137 \mathrm{C}$ & $0,318 \mathrm{~B}$ & $0,135 \mathrm{C}$ & $0,151 \mathrm{C}$ & $0,179 \mathrm{C}$ & $0,143 \mathrm{C}$ & $0,451 \mathrm{~A}$ & \\
\hline
\end{tabular}

Valores seguidas de uma mesma letra maiúscula nas linhas e minúsculas nas colunas não diferem entre si pelo teste de Tuckey (p < 0,05)

S1: composto $01+$ bagana + solo $(1: 2: 1) ;$ S2: composto $01+$ pó de coco verde + solo $(1: 2: 1) ;$ S3: composto $01+$ bagana (1:1); S4: composto 01 + pó de coco verde; S5: composto 02 puro; S6: composto 02 + bagana (1:1); S7: composto 02 + pó de coco verde; S8: comercial. R1: 228 células (14 ml); R2: 150 células (19 ml); R3: 126 células (30 ml). 